\section{Foreign Students in the Japanese University}

\section{John Clammer}

John Clammer is professor of sociology at Sophia University, Tokyo, Japan. Address: 4 Yonban-cho, Chiyodaku, Tokyo 102, Japan.

$\bigcup_{\mathrm{t}}^{\mathrm{n}}$ ntil very recently Japanese universities were not places to which students from within Asia or from around the world flocked for their higher education. While there was a long tradition of a very small number of students from China and prewar Japanese colonies of Korea and Taiwan going to Japan for university education, the numbers never approached those flowing from around the world to the universities of North America or Europe. In recent years, however, this pattern has begun to change and Japan has become a location of choice for many students seeking both undergraduate and graduate degrees. While in the last decade and a half there have always been fairly large numbers of students in Japan for language study, the shift to large numbers of full-time foreign students in the universities is posing problems and challenges hardly foreseen in the very recent past.

Until very recently Japanese universities were not places to which students from within Asia or from around the world flocked for their higher education.

Who are these students? Where are they coming from, how do they finance themselves, and what are the characteristic problems they face? These questions are interesting both from a comparative perspective and for the light they shed on the way in which Japanese society is evolving as it faces the end of the century and reconsiders its own place in the wider world. At the moment there are approximately 50,000 foreign students in Japan, many of them in language schools, vocational training institutes, and other nontertiary institutions. By the end of the century the Japanese Ministry of Education predicts that this number will double, and that a much higher proportion will be in the universities. It hopes to achieve this goal through a number of means: by making a wider range of Japanese universities known abroad; by encouraging universities to create courses and programs specifically for foreign studentsincluding courses in Japanese studies; by promoting exchange arrangements between Japanese and overseas universities; and by greatly increasing the number of schol- arships that the ministry awards to foreign students for study in Japan.

\section{At the moment there are approximately 50,000 foreign students in Japan, many of them in language schools, vocational training institutes, and other nontertiary institutions.}

Each of these points is of some interest. Many Japanese universities-outside the elite dozen or so-are not well known internationally, and very few advertise abroad or otherwise do much to make their existence known. Yet there are almost 500 tertiary-level institutions in Japanmany of them beginning to face the problem of falling enrollments due to the declining birth rate. While many foreign students-especially those already enrolled in a university elsewhere-might not want to spend four years in Japan or be able to afford to do so, there are plenty who are happy at the idea of a year abroad and the chance for exposure to a new culture and language. Programs of this kind, pioneered by Sophia University and the International Christian University — both in Tokyo — have been taken up by a range of colleges-especially those with strong international connections-often Christian ones—such as Meiji Gakuen University, which has recently started a year-long program specifically for students from English-speaking backgrounds.

Japan is now, in dollar terms, the world's biggest donor of foreign aid. Much of this aid goes to Asia-particularly in the form of funding for infrastructure projects. It has occurred to the Ministry of Education that an equally good form of aid is the provision of scholarships that bring foreign students to Japan for extended periods of time and provide education to those students of use to them at home that will also tie them to Japan linguistically and emotionally. The greatest expansion in such scholarships has gone to the development of postgraduate education and represents a massive investment. But while many students from around the world - the scholarships are allocated on a country basis, including developed countries-are attracted to Japan by this source of funding - which includes the provision of six months of intensive Japanese-language training before commencing a regular course-many others come with private funding or are sent by their own governments. Malaysia, for example, provides scholarships for students in technical subjects-usually engineering - at a number of Japanese universities. With its enormous economy, Ja- 
pan, of course, houses a substantial population of foreign diplomats and business people, some of whom also choose to send their children to universities in the country-especially ones that have courses in English, as a few do.

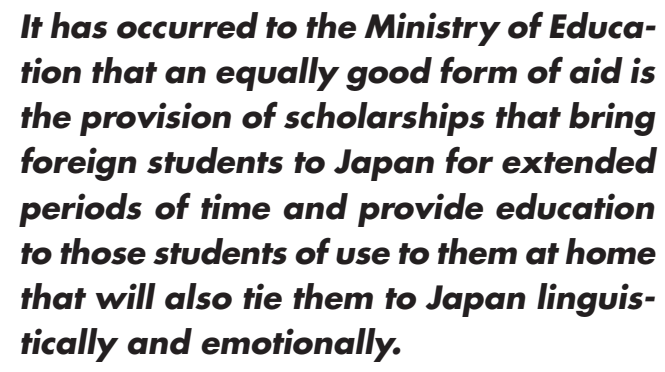

It has occurred to the Ministry of Education that an equally good form of aid is the provision of scholarships that bring foreign students to Japan for extended periods of time and provide education to those students of use to them at home that will also tie them to Japan linguistically and emotionally.

With this diversification of sources of funding and opportunities within the universities, the national balance among foreign students is also shifting. The majority of those in full-time study are still from the Kanji Area-parts of Asia where Chinese characters are used in writing. Large numbers are also coming from Southeast Asia-especially Malaysia and Thailand-and Latin America, with a smaller number from Africa, North America, and Europe. European and American students still tend to come for shorter periods-usually one year. These patterns reflect both Japan's geopolitical significance and the diversifying subjects that foreign students study, which now include almost all the fields taken by their Japanese peers. In some cases in graduate programs, the number of foreigners equals or exceeds that of Japanese, reflecting the fact that among developed nations, Japan has the smallest graduate school enrollments. This fact is partly a reflection of the labor market - which does not greatly reward the years spent in graduate school—and also that much fundamental research in Japan is carried out in research institutes connected to large corporations that in the West would be in universities.

\section{With this expansion of numbers, some fairly severe problems have become apparent.}

With this expansion of numbers, some fairly severe problems have become apparent. These include adaptation to culture and language, the absorption of the very high cost of living in Japan, and access to housing. Many landlords are still unwilling to rent to foreigners-especially poor ones like students. While the government has responded by building dormitories for a proportion of the government scholars and while most universities have some housing, the supply is still far short of the demand, and a depressing number of foreign students end up living in remote, expensive, and substandard accommodation. The absorption of foreign students and their acceptance as social equals is one of the great tests of the "internationalization" that the Japanese claim is happening as one of the most positive features of social development in this-in many ways-introverted nation. With more foreigners graduating from Japanese universities, the international educational system stands to benefit as more becomes known about this large—but still quite unknown-sector of higher education, its distinctive practices, and the role it has played in Japan's phenomenal postwar development.

\section{Virtual University Exchange Program}

\section{Students from Central and Eastern Europe and the Former Soviet Union in the United States}

\section{Iveta Silova}

Iveta Silova recently completed a masters degree in international education at Teachers College, Columbia University.

Since the collapse of communism and the breakdown of the Soviet Union, the number of students from Eastern and Central Europe and the former Soviet Union coming to the United States to study has rapidly increased. According to the Open Doors Report (1996), enrollment of students from these countries in American colleges and universities has tripled from 4,780 five years ago to 18,032 today. New opportunities for study abroad are provided by a growing number of international exchange programs supported by the American government, private foundations, and higher education institutions. Assuming that education is a powerful tool for political, economic, and social development, many of these exchange programs aim to encourage transformation of the former communist bloc. An undergraduate exchange program-the Virtual University, initiated by the Open Society Institute and a part of the Soros foundations network-attempts to support educational development in Eastern and Central Europe and the former Soviet Union by exposing grantees to multicultural academic settings, a liberal arts curriculum, and different models of classroom instruction. 